\title{
A Microcomputer-Based Novel Deposition Controller for Preparing Films with Graded Composition
}

\author{
L. Shivalingappa, K. Narasimha Rao, and S. Mohan
}

\begin{abstract}
A novel microcomputer-based electron beam (EB) deposition technique has been developed for preparing thin films with graded composition. A conventional EB gun crucible has been modified to accommodate two constituent materials. Necessary electronic hardware and a software-based INTEL 8085 microcomputer have been built to provide the crucible rotation with the required speed and for changing the emission currents for the $\mathrm{EB}$ gun. Mixed oxide films of $\mathrm{CeO}_{2}$ and $\mathrm{SiO}_{2}$ with composition varying along their thicknesses have been prepared. The composition gradation has been altered by varying the deposition rate and rotational speed of individual constituents. The atomic percentages of $\mathrm{Ce}, \mathrm{Si}$, and $\mathrm{O}$ have been computed from deposition parameters and correlated with the data obtained from Auger spectroscopy.
\end{abstract}

Index Terms-Graded composite films, novel deposition controller.

\section{INTRODUCTION}

C OMPOSITION control has been an essential factor in deciding the quality of a variety of thin film devices. Of late, it is being increasingly felt that the performance of some devices could be enhanced if the properties of the film is matched with its substrate on one side and the air surface on the other; for example, for antireflection optical devices, the refractive index should be almost equal to that of the substrate, whereas, at the top layer, it should be very nearly equal to that of the surrounding atmosphere [1].

A variety of methods have been used to realize the variation in composition along the film thickness. Multiple sources have been used both in evaporation [2]-[6] and sputtering techniques [9]-[11]. Although this coevaporation method is successful, it requires two electron beam (EB) guns which occupy a large space in the chamber and individual rate controllers for rate monitoring and a more sophisticated process control mechanism. With two EB guns located at different places in the chamber, it is essential to ensure that the film composition is uniform over the substrates in batch coating. In this coevaporation method, the deposition rate of one source has been gradually increased while decreasing the deposition rate from the other source. In this process, the quantity of the first material was less

Paper MSDAD-I 99-009, presented at the 1995 Industry Applications Society Annual Meeting, Lake Buena Vista, FL, October 8-12, and approved for publication in the IEEE TRANSACTIONS ON INDUSTRY APPLICATIONS by the Industrial Automation and Control Committee of the IEEE Industry Applications Society. Manuscript submitted for review July 1, 1996 and released for publication January 6, 2000.

The authors are with the Vacuum and Thin Films Laboratory, Department of Instrumentation, Indian Institute of Science, Bangalore 560 012, India (e-mail: 1shivu@isu.iisc.emet.in; knrao@isu.iisc.emet.in; smohan@isu.iisc.emet.in).

Publisher Item Identifier S 0093-9994(00)03167-4. in the bottom layer, whereas that of the second material was less in the top layer. It is also possible to control the gradation in reactive gas content of a film by proper control of mass flow rate of the reactive gases with respect to the inert gas medium. This process uses process controls with changing flow rates of reactive gases.

Realizing the importance of the films of varying composition, the problems faced in coevaporation technique, and to reduce the process control complications in the system, a novel rotating crucible EB gun technique has been fabricated. This technique has already been used to prepare homogeneous films with ultrathin individual films in the stack [12]. It is now being extended to prepare films with continuous gradation in composition.

This paper details the design of hardware and software functions of the rotating $\mathrm{EB}$ evaporation technique for preparing graded index film of $\mathrm{CeO}_{2}$ and $\mathrm{SiO}_{2}$ materials. The gradation of the films with respect to their thicknesses along the depth was analyzed using Auger depth profile and correlated with the deposition parameters.

\section{DESCRIPTION OF THE SYSTEM}

A 6-kW EB gun crucible is modified so that it can be rotated at different speeds during evaporation. The details of the technique for preparing homogeneous films has already been presented in [12]. The schematic view of the deposition system is shown in Fig. 1(a). The crucible is made of oxygen-free high-conductivity (OFHC) copper. A groove is made along the circumference of the crucible which is partitioned into two sectors for loading the evaporating materials and is shown in Fig. 1(b). The crucible is rotated using a stepper motor $(A)$ fixed outside the vacuum system. A Wilson seal $(B)$ fixed to the base plate $(C)$ of the deposition system is used as the rotating element for coupling the stepper motor and the electron gun crucible $(D)$. The shaft of the Wilson seal is coupled to the EB gun through a chain and sprocket arrangement $(E)$. A small nonmagnetic metal projection $(G)$ is embedded to the circumference of the crucible. When this projection faces a position sensor $(F)$ (proximity switch [13]) positioned close to the crucible, the sensor gives a voltage output.

The following procedure is used for preparing films with graded composition. The two materials with different vaporization temperatures are loaded into the two partitions of the crucible [Fig. 1(b)]. When the initial position of the crucible is sensed, specified speed of rotation of the crucible and filament emission current are set for evaporating the first material in the crucible. These values are retained until the crucible crosses 

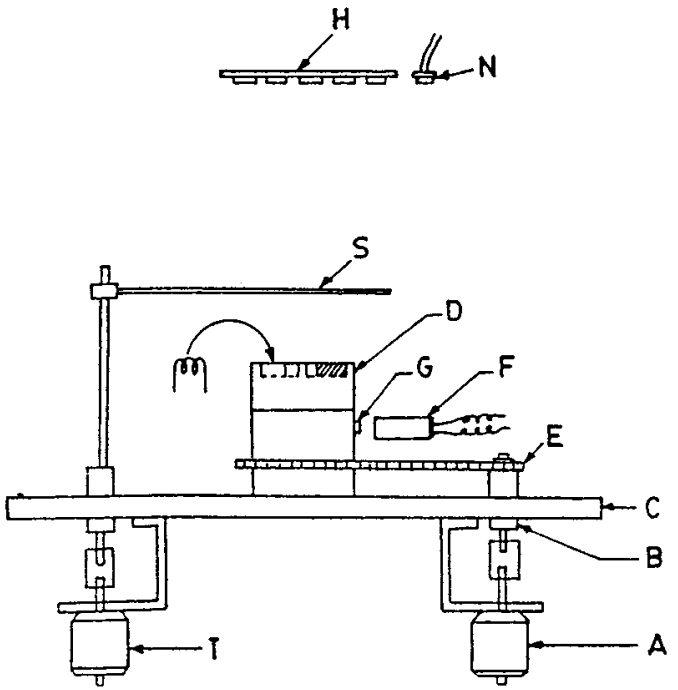

(a)

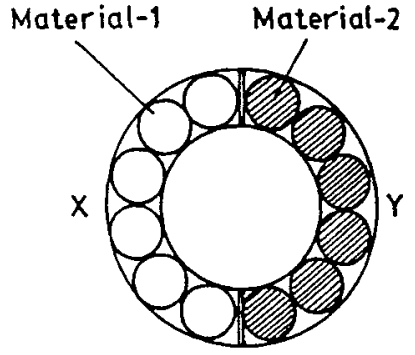

(b)

Fig. 1. (a) Schematic view of the deposition system. A: stepper motor for crucible rotation; $B$ : wilson seal; $C$ : base plate; $D$ partitioned crucible; $E$ : chain and sprocket arrangement; $F$ : position sensor, $G$ : metal projection; $H$ : substrate holder; $N$ : crystal sensor; $S$ : source shutter; and $T$ : stepper motor for source shutter. (b) Partitioned crucible.

the first evaporating material. When the second evaporating material faces the EB, the emission current and speed will change automatically to the values set corresponding to the second material, which depend on the vapor pressure of the material and the required rate of deposition. These values of current and speed are retained until the crucible crosses the second evaporating material. When the beam again faces the first material, the current and speed automatically get set to the values set for the first material. At the partition of the copper crucible, the emission currents were reduced to zero to avoid the contamination of copper in the film. By an appropriate choice of deposition rates and rotation speeds, it is possible to see that the materials get mixed up at the atomic level. For realizing films with gradation in composition along the film thickness deposition rate of one of the materials is gradually increased while decreasing the deposition rate of the other material.

The thickness and the rate of deposition of two film materials are monitored using a homemade quartz crystal thickness monitor [14]. The sensing element $(N)$ of the crystal monitor is arranged very close to the substrate holder $(H)$ as shown in Fig. 1(a).

\section{ELECTRONIC DESIGN}

The details of the hardware and software for this technique for preparing graded composition films are given below.

\section{A. Hardware}

The emission current and the speed of rotation of the crucible are controlled by making use of an INTEL 8085 microcomputer kit. It is always ideal to use a sophisticated computer for this purpose. However, in a program oriented toward industrial applications, where cost has to be kept under control, it was decided to use a conventional 8085 microcomputer. It is also to be noted that this is an attempt to highlight the use of this technique for industrial purposes with minimum expenditure. The 8085 microcomputer kit consists of a microprocessor (8085), keyboard display controller (8279), programmable peripheral interface (PPI) (8255), random access memory (6116), erasable programmable read-only memory (2716), decoders, and drivers. The basic clock frequency of the 8085 kit is $3.072 \mathrm{MHz}$. The address, data, and control bus are brought to the edge connector for interconnection. The block diagram of this kit for preparing graded index films is shown in Fig. 2. This kit consists of two PPI (8255) ports. One PPI (8255) is used for driving the stepper motors: 1) coupled to the crucible via Wilson seal $(B) ; 2)$ coupled to the source shutter; and 3 ) for receiving an input signal from the position sensor used for sensing the initial position of the crucible. The second PPI (8255) is used for driving the emission current circuit with the help of a 12-b digital-to-analog converter (DAC) [15]. The resolution of the DAC is $0.5 \mathrm{mV}$ (for $2 \mathrm{v}$ full-scale output).

The input to the DAC is fed from the second PPI (8255). Since there are 12 inputs to the DAC and since each of the three ports of the 8255 is only $8 \mathrm{~b}$ wide, the lower section of $8 \mathrm{~b}$ is connected to one port while the upper section of $4 \mathrm{~b}$ is connected to another port. Outputting 12 bits of data at a time would involve again outputting $8 \mathrm{~b}$ first and then the remaining $4 \mathrm{~b}$. In the time between the two writes, there is a danger of the output going to an unwanted value because the $4 \mathrm{~b}$ of data can change when the $8 \mathrm{~b}$ of data are being written and vice versa. This is overcome by use of latches on the input lines which are loaded separately and then strobed together to pass all $12 \mathrm{~b}$ of data to the DAC at the same time. While this method ensures simultaneous transfer of $12 \mathrm{~b}$ of data, one other point that has to be tackled is that of unwanted values existing at the inputs during power-on reset of the 8255 .

During power-on reset, the outputs of the 8255 will be tristated and this will be conceived as some value by the DAC and an output equivalent of the input will be presented to the error amplifier of the emission current power supply. This output is avoided by using two octal D-type flip flops (74LS273). Since the outputs of these flip flops are always low, it has to be triggered by the clock with its clear input high. Again, the same clock and clear facility could be used for transmitting $12 \mathrm{~b}$ of data simultaneously. The clock and clear signals to the 74LS273 are provided by the port $\mathrm{C}$ of the 8255 taking advantage of the bit set/reset facility associated with this port. Since the DAC uses a complementary binary input, inverters (74LS04) have been incorporated into the circuit (Fig. 3). The DAC provides a current 


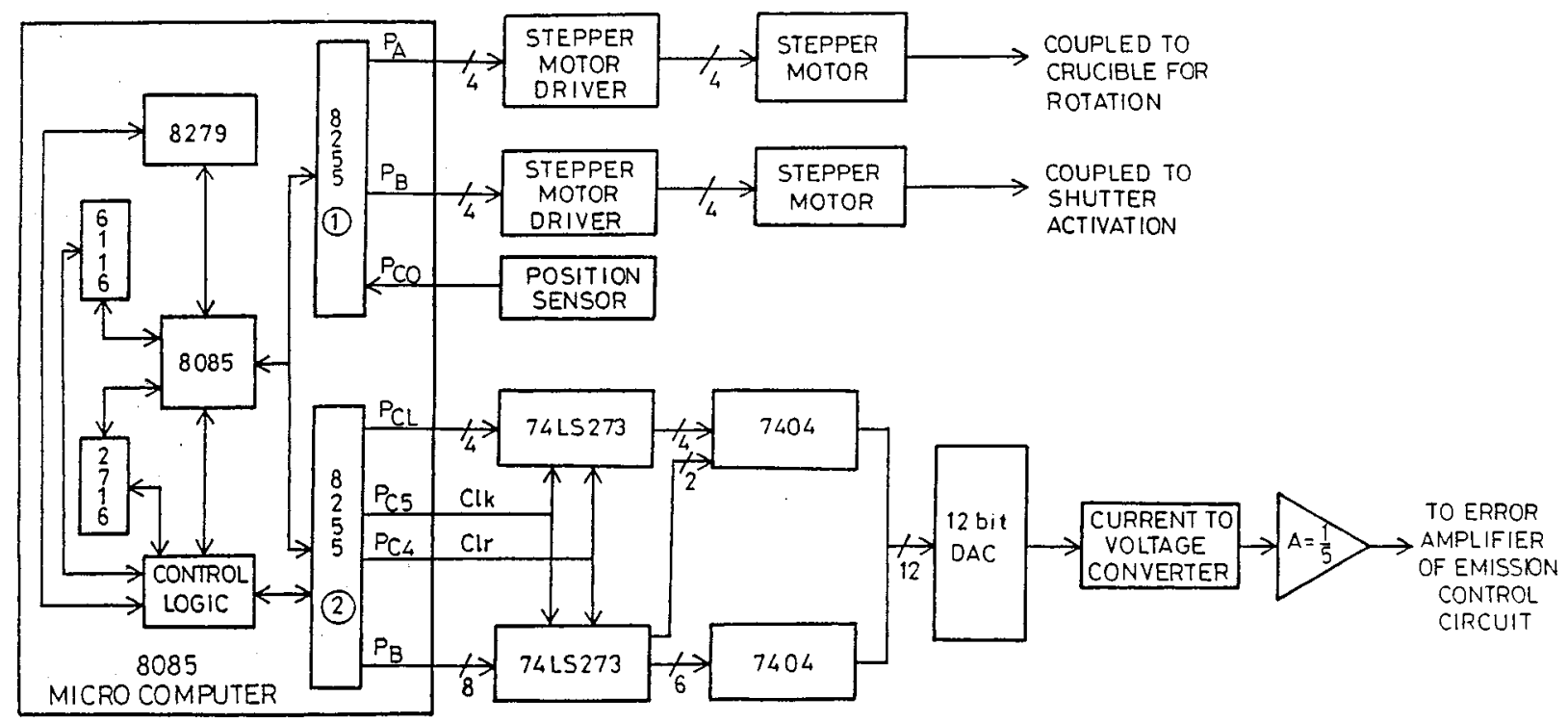

Fig. 2. Block diagram of deposition controller.

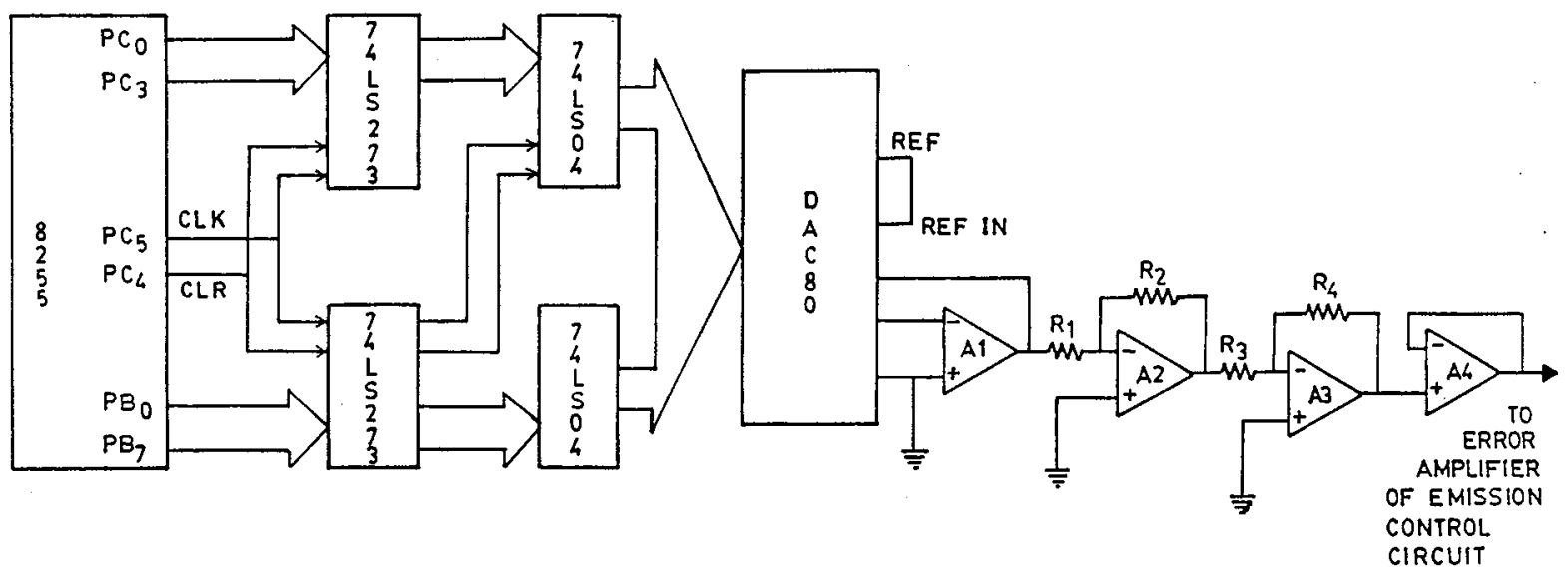

Fig. 3. Digital-to-analog converter (DAC-80) interfacing circuit

output which is converted to voltage by making use of a current-to-voltage converter using op amp $A_{1}$. The built-in resistor of the DAC has been used in the feedback circuit. This circuit presents a maximum of $9.9976 \mathrm{~V}$ when all the inputs of the DAC are at logical 1 state (i.e., the input of inverters). The output of the DAC is fed to op amp $A_{3}$, where the actual voltage is stepped down by five times. This output is buffered using op amp $A_{4}$. The maximum output voltage available at $A_{4}$ is $2 \mathrm{~V}$, for an input code of FFF to the DAC. That is, the output voltage can be varied from 0 to $87 \mathrm{~mA}$ for a corresponding input variation from 0 to $2 \mathrm{~V}$.

One stepper motor $(A)$ is used for crucible rotation and the second stepper motor $(T)$ [Fig. 1(a)] for opening and closing of the source shutter before and after the deposition process. The lower $4 \mathrm{~b}$ of port $\mathrm{A}$ of the 8255 is used for driving the stepper motor. The lower $4 \mathrm{~b}$ of port $\mathrm{B}$ is used for opening and closing of the source shutter with the help of stepper motor $(T)$. Port $\mathrm{Pc}_{o}$ is used as an input port for sensing the initial position of the crucible from the position sensor.

\section{B. Software}

The operation of the controller for sequential evaporation of two materials, each of them filled in one-half the area of the crucible with emission current $I_{1}$ increasing from 0 to $100 \%, I_{2}$ decreasing from 100 to $0 \%$, and with crucible speeds $S_{1}$ and $S_{2}$ for materials 1 and 2, respectively, is shown in Fig. 4. When the controller is switched on, the stepper motor rotates the crucible at a specified speed until the position sensor senses the initial position. This position of the crucible is shown as " $S$ " in Fig. 4. At this position, material 1 is facing the EB. An emission current $I_{1}$ (for example, $0 \%$ ) is set for evaporating material 1 using the 12-b DAC, and the crucible is rotated at a specified speed $S_{1}$. The emission current $I_{1}$ and $S_{1}$ are maintained until the crucible completes the first half revolution (from the initial position " $S$ " as estimated from the number of pulses given to stepper motor). At this stage, the emission current $I_{2}$ (for example, 100\%) is set with the aid of the DAC for evaporating material 2 and the crucible is now rotated at a speed $S_{2}$. Again, emission current $I_{2}$ and speed $S_{2}$ are maintained until the crucible completes the 


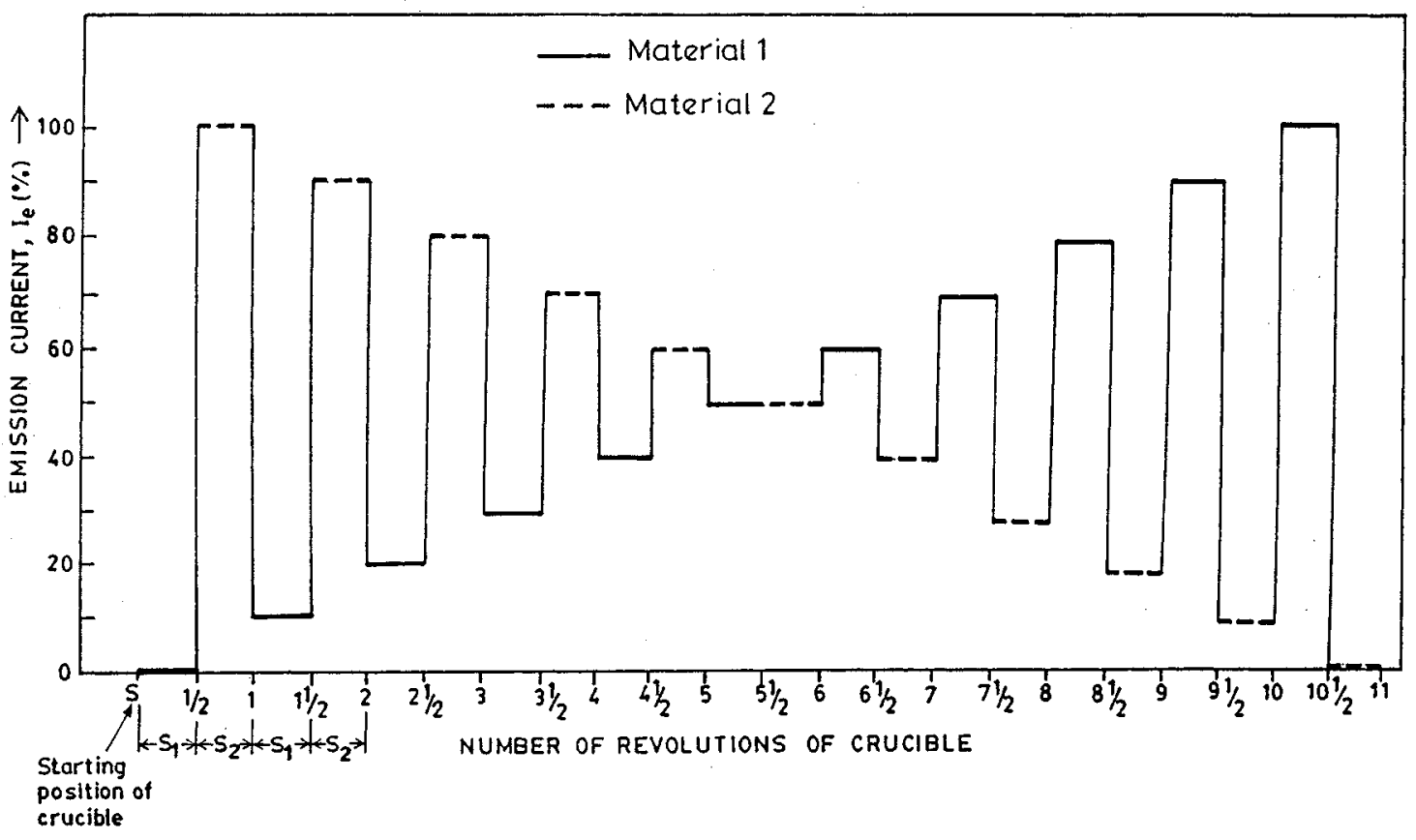

Fig. 4. Operation of the controller.

second half revolution and, in turn, receives a signal from the position sensor. Then, as the EB sees the material 1, the emission current $I_{1}$ is then increased by a required value (for example, from $0 \%$ to $10 \%$ ) and the crucible speed is changed from $S_{1}$ to $S_{2}$. When the crucible completes the third half revolution, the emission current $I_{2}$ is reduced (for example, from $100 \%$ to $90 \%$ ) and the speed of the crucible is changed from $S_{1}$ to $S_{2}$. This process is repeated continuously until the current $I_{1}$ reaches $100 \%$ and current $I_{2}$ decreases to $0 \%$.

It is possible to modify the software such that the current can be kept constant for a fixed number of revolutions to alter the gradation. The gradation could also be altered by appropriately selecting deposition rates and crucible rotation speeds. When the controller reaches the set value of currents, the deposition process will be terminated automatically by closing the evaporation shutter. The flow chart of the program for implementing the above task is given in Fig. 5. This process can be carried out in the reverse process also by changing the contents in memory locations, i.e., emission current $I_{1}$ for material 1 can be decreased from $100 \%$ to $0 \%$ and $I_{2}$ for material 2 can be increased from $0 \%$ to $100 \%$.

\section{Features of the Technique}

- The technique is useful for preparing graded index films for two evaporating materials.

- The gradation of each material can be varied from $0 \%$ to $100 \%$ or vice versa, i.e., the gradation of material 1 can be increased from $0 \%$ to $100 \%$ and the gradation of material 2 is decreased from $100 \%$ to $0 \%$.

- Emission currents of each material can be changed either for one revolution of the crucible or for any finite number of revolutions of the crucible.
- The thicknesses of individual layers can be controlled according to a predetermined scheme.

- The gradation of individual materials can be varied from $0 \%$ to $100 \%$, i.e., the concentration of each evaporating material need not be started from $0 \%$ to $100 \%$; it can be started at any intermediate concentration. For example, the concentration of material 1 can be started from $10 \%$ and increased up to $80 \%$. Similarly, for material 2 , the concentration can be decreased from $80 \%$ to $10 \%$ or from $100 \%$ to $0 \%$.

- Automatic process termination is possible by opening and closing of the evaporation shutter when the concentration of each material reaches the preset value.

- Automatic degassing process is incorporated for degassing the individual evaporating material in the prescribed time. When the materials reach the maximum set value of degassing power, the control will automatically switch over to the main deposition process by opening the evaporation shutter.

\section{EXPERIMENTAL RESULTS AND DISCUSSION}

Two dielectric materials of high and low refractive indexes have been chosen to obtain the variable refractive indexes along the depth of the film by controlling the deposition rates of individual materials. The materials used are cerium dioxide and silicon dioxide tablets. The purity of material is $99.8 \%$ (Balzers Ltd. USA). The two materials are loaded in the grooved crucible in two separate partitions. Before the deposition process starts, the emission currents $I_{1}$ and $I_{2}$ are ramped slowly until the materials reach the evaporation temperature. The required degassing power and the degassing duration for each material are software controllable. When the materials attain the evapo- 


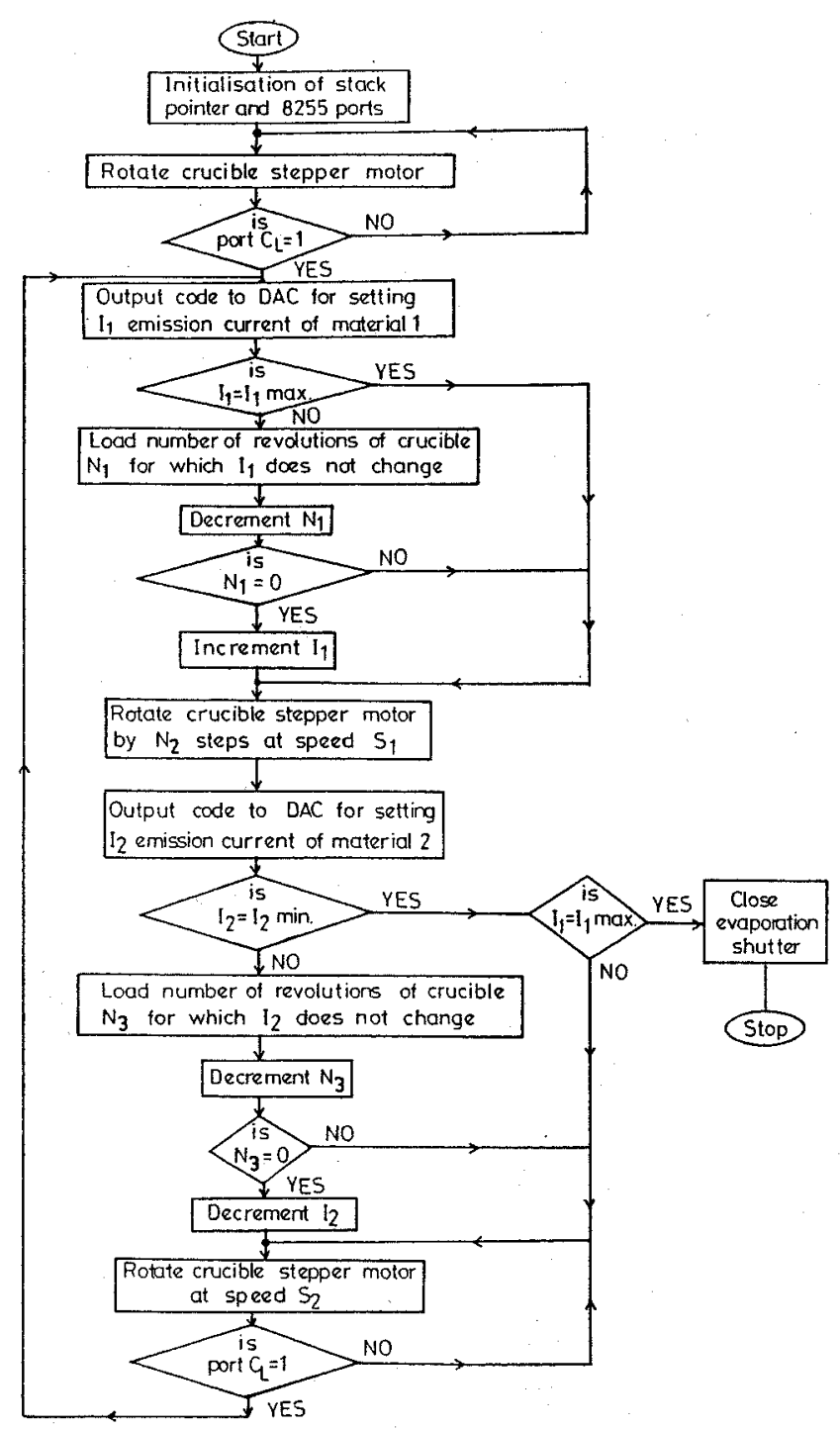

Fig. 5. Flow chart for the preparation of graded index films with increase in $\mathrm{CeO}_{2}$ content and decrease in $\mathrm{SiO}_{2}$ content from substrate-film to film-air interface.

rating temperature, the controller switches over to the main deposition process.

The films were deposited onto an optically polished fused silicon substrate of 19-mm diameter and 3-mm thickness, a silicon wafer, and a copper substrate at a pressure of $1 \times 10^{-6}$ mbar. The deposition chamber is evacuated using CTI cryo torr $^{-8}$ cryo pump backed by a rotary pump. The distance between the EB gun and the substrate holder was $25 \mathrm{~cm}$.

Mixed oxide graded index films of $\mathrm{CeO}_{2}$ and $\mathrm{SiO}_{2}$ of varying compositions along their thicknesses have been prepared by a proper choice of emission currents and speed of rotation of the crucible which, in turn, control the deposition rate of the two constituents; the results are presented in Table I. Taking into account the deposition rate and the EB, the probable thickness of each constituent with respect to its thickness has been calculated and shown in Table I.

The composition of graded index films deposited at ambient temperature was analyzed using an Auger depth profile spec-
TABLE I

COMPOSITION COMPUTEd IN TERMS OF Weight AND ATOMIC PERCENT FOR GRADED INDEX FILM With DECREASE IN $\mathrm{CeO}_{2}$ CONTENT AND INCREASE OF $\mathrm{SiO}_{2}$ CONTENT FROM SubSTRATE-FILM TO FILM-AIR INTERFACE.

\begin{tabular}{|c|c|c|c|c|c|c|c|c|}
\hline \multirow{4}{*}{$\begin{array}{l}\text { Thickness } \\
\text { (depth of } \\
\text { fila) } \\
\text { (A) }\end{array}$} & \multicolumn{8}{|c|}{ Composition conputed fron } \\
\hline & \multicolumn{5}{|c|}{ Deposition parsmeters } & \multicolumn{3}{|c|}{ AES } \\
\hline & \multicolumn{2}{|c|}{ Weight $\%$} & \multicolumn{3}{|c|}{ Atonic $*$} & \multicolumn{3}{|c|}{ Atonio $x$} \\
\hline & $\mathrm{CeO}_{2}$ & $\mathrm{SiO}_{2}$ & $\mathrm{C}_{\theta}$ & $\mathrm{Si}$ & 0 & $\mathrm{Ce}$ & si & 0 \\
\hline 0 & 95.2 & 4.8 & 28.9 & 4.38 & 86.6 & 32.7 & 4.48 & 62.8 \\
\hline 290 & 83.2 & 6.8 & 27.4 & 5.82 & 66.6 & 29.7 & 8.7 & 63.6 \\
\hline 893 & 85.6 & 14.4 & 22.6 & 10.7 & 66.6 & 25.3 & 8.8 & 84.8 \\
\hline 1333 & 81.5 & 18.5 & 20.2 & 13.1 & 86.8 & 22.2 & 12.8 & 64.8 \\
\hline 1636 & 77.0 & 23.0 & 18.0 & 15.2 & 86.6 & 20.4 & 15.1 & 84.5 \\
\hline 2250 & 72.4 & 27.8 & 15.8 & 17.4 & 66.8 & 17.3 & 18.1 & 64.8 \\
\hline 2714 & 67.3 & 32.7 & 13.8 & 18.5 & 88.6 & 14.1 & 21.7 & 64.2 \\
\hline 3184 & 82.0 & 38.0 & 12.1 & 21.2 & 66.8 & 12.4 & 23.7 & 63,8 \\
\hline 3659 & 56.0 & 44.0 & 10.3 & 23.1 & 86.6 & 8.35 & 28.7 & 83.8 \\
\hline 4149 & 36.0 & 64.0 & 5.6 & 27.6 & 66.8 & 5.5 & 30.0 & 64.5 \\
\hline 4650 & 20.0 & 80.0 & 2.6 & 30.7 & 86.6 & 3.1 & 32.8 & 64.1 \\
\hline
\end{tabular}

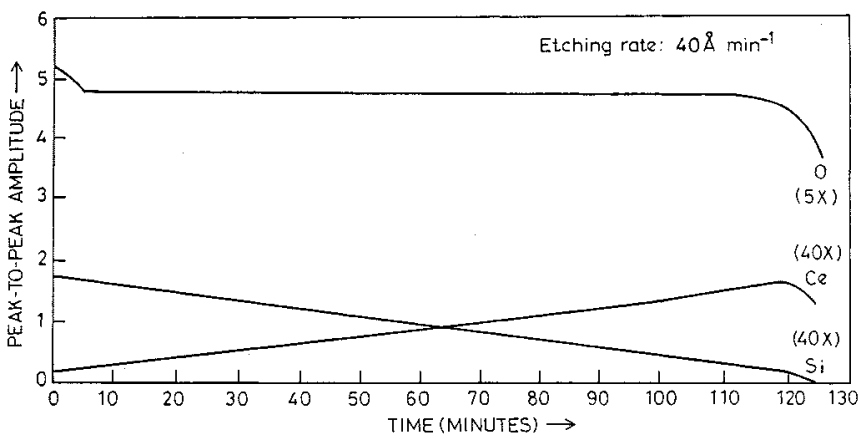

Fig. 6. Auger depth profile of graded index film with decrease in $\mathrm{CeO}_{2}$ content and increase of $\mathrm{SiO}_{2}$ content from substrate-film to film-air interface.

trometer (Model 541C, Phillipse, USA). Fig. 6 shows the Auger spectra profile of the graded films of $\mathrm{CeO}_{2}-\mathrm{SiO}_{2}$ deposited at ambient temperature. The atomic percents of cerium, silicon, and oxygen were computed from depth profile at different depths. These values are also tabulated in the Table I. The zero thickness corresponds to the substrate-film interface and with the increase in thickness, the layers approach the film-air interface. The concentration of $\mathrm{CeO}_{2}$ decreased from $95 \%$ to $20 \%$ (by weight) whereas the concentration of $\mathrm{SiO}_{2}$ increased from $5 \%$ to $80 \%$ from substrate-film to film-air interface. It is seen from Table I that, when the deposition was continuing, the atomic and weight percent of $\mathrm{CeO}_{2}$ decreased gradually and that of $\mathrm{SiO}_{2}$ was increased gradually, whereas the atomic percent of oxygen was constant throughout the process. This shows that the films are graded in composition along their thicknesses. The atomic percent computed from the Auger depth profile and from deposition parameters are in good agreement with each other within the instrumental accuracy. 


\section{CONCLUSION}

A novel microcomputer-based rotating crucible electron source deposition technique has been developed in which graded index mixed oxide films of varying composition along the film thicknesses could be prepared. The mechanical design of the assembly, the relevant hardware, and software of the deposition controller for preparing films with composition gradation have been discussed. Graded composition films of $\mathrm{CeO}_{2}$ and $\mathrm{SiO}_{2}$ of different composition with respect to film thickness have been prepared, and the composition variation was analyzed using an Auger depth profile. The atomic percent computed from the Auger depth profile is in good agreement with the values computed from the deposition parameters.

\section{ACKNOWLEDGMENT}

The authors express their sincere thanks to T. V. Balasubramanian, Scientist, Defence Metallurgical Research Laboratory, Hyderabad, India, for providing Auger spectra of films and helpful discussion. Thanks are also due to all the staff of the Vacuum and Thin Film Laboratory, Department of Instrumentation, Indian Institute of Science, Bangalore, for their cooperation and helpful discussion.

\section{REFERENCES}

[1] I. T. Ritchie and B. Window, "Applications of thin graded index films to solar absorbars," Appl. Opt., vol. 16, no. 5, pp. 1438-1443, May 1977.

[2] R. Bertram, M. F. Ouelletts, and P. Y. Tsee, "Inhomogeneous optical coatings: An experimental study of a new approach," Appl. Opt., vol. 28, no. 14, pp. 2935-2939, July 1989.

[3] R. Jacobsson, "Inhomogeneous and coevaporatated homogeneous films for optical applications," Phys. Thin Films, vol. 8, no. 3, pp. 51-97, 1975.

[4] R. Jacobsson and J. O. Martensson, "Evaporated inhomogeneous thin films," Appl. Opt., vol. 5, no. 1, pp. 29-34, Jan. 1966.

[5] S. K. Sharma, V. N. Yadava, and K. L. Chopra, "Variable and gradient refractive index multilayer films of different materials," Jpn. J. Appl. Phys., Suppl. 2, pt. 1, pp. 685-688, 1974.

[6] - "Optical behavior of gradient-index multilayer films," Thin Solid Films, vol. 21, no. 2, pp. 297-312, 1974.

[7] W. J. Gunning, R. L. Hall, F. J. Woodberry, W. H. Southwell, and W. S. Gluck, "Codeposition of continuous composition rugate filter," Appl. Opt., vol. 28, no. 14, pp. 2945-2948, July 1989.

[8] W. H. Southwell, "Gradient-index antireflection coatings," Opt. Lett., vol. 8, no. 11, pp. 584-586, Nov. 1983.

[9] C. Misiano and E. Simonetti, "Co-sputtered optical films," Vacuum, vol. 27, no. 4, pp. 403-408, 1977.

[10] A. B. Harker and J. F. Denatale, "Tailored target approach to the deposition of gradient index optical filters," Thin Solid Films, vol. 168, no. 9, pp. 185-192, 1989 .

[11] E. P. Donovan, D. V. Vechten, A. D. F. Kahn, C. A. Carosella, and G. K. Hubler, "Near infrared rugate filter fabrication by ion beam assisted deposition of $\mathrm{Si}_{(1-x)} \mathrm{N}_{x}$ films," Appl. Opt., vol. 28, no. 14, pp. 2940-2944, July 1989.
[12] L. Shivalingappa, K. N. Rao, and S. Mohan, "Rotating crucible electron beam evaporation technique for the deposition of multicomponent oxide films," Vacuum, vol. 44, no. 11, pp. 1031-1035, 1993.

[13] Transducer and Allied Products Manual for Proximity Sensors, vol. 1, Transducers Ltd., Bangalore, India, 1989, pp. 5-10.

[14] L. Shivalingappa, "Design, development and performance evaluation of a digital quartz crystal monitor for thin film deposition," J. Indian Inst. Sci., vol. 71, no. 5/6, pp. 308-311, 1991.

[15] Analog Devices Data-Acquisition Data Book, vol. 1, Analog Devices, Norwood, MA, 1984, pp. 285-289.

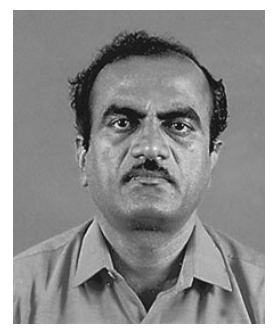

L. Shivalingappa received the M.Sc. degree in physics with a specialization in electronics and the P.G.D.I. degree (a specialized postgraduate diploma in electronics design technology and instrumentation) from Bangalore University, Bangalore, India, in 1976 and 1977, respectively, and the M.Sc.(Engg.) and Ph.D. degrees from the Indian Institute of Science, Bangalore, India, in 1989 and 1994, respectively.

In 1979, he joined the Indian Institute of Science, Bangalore, India, where he is currently a Senior Scientific Officer in the Department of Instrumentation. He has designed and developed many new instruments/techniques which are useful in electronics and thin film laboratories. He has undergone a three-week advanced training program at Leybold Hearous Company, Germany. He received a three-month JSPS Fellowship Programme to carry out research at Shinshu University, Nagano, Japan. During this period, he was involved in the preparation and characterization of ferroelectric and ferromagnetic thin films. During 1996, he was a Visiting Scientist at Teer Coatings Ltd., U.K. During this period, he was involved in the design and development of vacuum and thin film deposition process control instrumentation using Advanced Labview graphical software and preparation and characterization of DLC and other types of coatings for tribological applications. He has traveled widely, giving invited talks at international symposia and R\&D laboratories in the U.S., U.K., Germany, France, and Japan. His current interests include thin film instrumentation, deposition techniques, and biomedical instrumentation. He has authored numerous papers published in national and international journals.

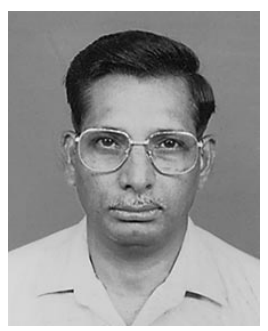

K. Narasimha Rao received the M.Sc.(Tech.) degree in applied physics from Andhra University, Waltair, India, and the Ph.D. degree from the Indian Institute of Science, Bangalore, India, in 1971 and 1988, respectively.

Since 1988, he has been with the Vacuum and Thin Films Laboratory, Department of Instrumentation, Indian Institute of Science, Bangalore, India. His current interests include thin films, vacuum technology, optical instruments, and lasers. 


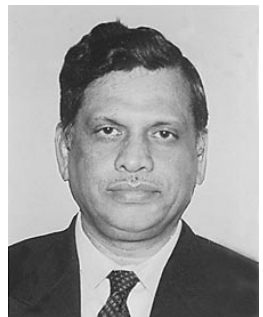

S. Mohan received the Ph.D. degree in thin films from Sri Venkateswara University, Tirupati, India, in 1974.

Since December 1993, he has been a Professor in the Department of Instrumentation, Indian Institute of Science, Bangalore, India. Before joining the Indian Institute of Science in 1977, he served as a Lecturer in Physics at S.V. University for seven years. His contributions are in the areas of optical thin film devices, superconductivity, tribology, and thin film devices for space, defense, atomic energy, and biomedical applications. He has authored about $100 \mathrm{R} \& \mathrm{D}$ publications in refereed journals, 100 papers in national and international symposia, and ten review articles. He is a Member of the Editorial Board of the journals Vacuum (Pergamon Press) and Pramana (Indian Academy of Sciences) and the Bulletin of Surface Engineering. During 1997-1999, he was the Director of Central Scientific Instruments Organization, one of the largest of the CSIR instruments laboratories. During his term as Director, he prepared the vision for this laboratory, motivated 700 staff members, and initiated $R \& D$ projects in various areas of instrumentation. He was also successful in establishing productive interaction with industry and transferred a number of technologies. He identified a large number of international collaboration programs and initiated a synergy program among $R \& D$ laboratories, industriy, and funding agencies. He is a member of a number of advisory committees at the national level. He was a Visiting Professor at Forschung Centrum, Julich, Germany, during 1990 and the University of Pennsylvaia in 1994. He has traveled widely, chairing sessions and giving invited talks at international symposia and R\&D laboratories in the U.S., U.K., U.S.S.R., Germany, Canada, Yugoslavia, Malaysia, Singapore, and Australia. He has been actively contributing to the activities of professional societies, as Convener of the Thin Films Subject Group of the Materials Research Society of India, as Editor of the Journal of the Instrument Society of India, General Secretary of the Laser Society of India, and Executive Committee Member representing southern India in the Indian Vacuum Society. He is also currently the President of the Instrument Society of India.

Prof. Mohan was selected as a UGC National Associate in 1977. In 1981, he was honored by the Andhra Pradesh Academy of Sciences with a Young Scientist Award. The Materials Research Society of India honored him with the MRSI Medal in 1992. The Department of Science and Technology identified him as an SERC Lecturer in 1993. 